\title{
Characterization of Pure and Composite Resorcinol Formaldehyde Aerogels Doped with Copper
}

\author{
S. M. Attia ${ }^{\mathrm{a}, \mathrm{b} 1 *}$, W. I. A. Ismail ${ }^{\mathrm{a}}$ and M. M. Mossad ${ }^{\mathrm{a}}$ \\ ${ }^{a}$ Physics Department, Faculty of Science, Kafrelsheikh University, Kafr El-Sheikh, \\ Egypt and ${ }^{b}$ Physics Department, College of Applied Sciences, Umm Al-Qura \\ University, PB 7296, Makkah 21955, Saudi Arabia
}

\begin{abstract}
SERIES of resorcinol formaldehyde aerogels (RF aerogels) composite with nanoparticles $A$ of copper has been prepared by the sol-gel method. Four samples of pure RF aerogels were prepared at different concentrations of $\mathrm{NaOH}$ as a catalyst $(0.015,0.017,0.022$ and 0.024 wt. \%) and four samples of composite RF aerogels doped with $\mathrm{Cu}$ were prepared at different concentration of $\mathrm{Cu}\left(7.8 \times 10^{-5}, 1.56 \times 10^{-4}, 2.34 \times 10^{-4}\right.$, and $3.11 \times 10^{-4} \mathrm{wt} . \% ; \mathrm{NaOH}$ concentration $=$ 0.015 wt. \%). UV-visible spectrum of $\mathrm{Cu}$ colloidal showes an absorbance peak at $608 \mathrm{~nm}$, while UV-visible spectra of pure and composite RF aerogels show a steep decrease of absorption after $500 \mathrm{~nm}$ making RF aerogel color reddish brown. Results of FTIR spectra of pure and composite $\mathrm{RF}$ aerogels show the existence of six absorption bands ensuring the formation of RF aerogels. FTIR results ensured also that $\mathrm{Cu}$ particles do not affect the aerogel network. SEM images of pure and composite RF aerogels show that the textural arrangement of RF aerogels can be described as densely packed small nodules. The particle size analyzer ensured that the average particle size for $\mathrm{Cu}-\mathrm{RF}$ aerogel composite increases with increasing the copper content.
\end{abstract}

Keywords: RF Aerogels, Nano-composite, Supercritical drying, $\mathrm{Cu}$ nanoparticle.

\section{Introduction}

Aerogels are nano-porous materials with low bulk density, high surface area, continuous porosity and high crosslinking structure $[1,2]$. Aerogels are widely used in thermal insulation, nuclear particle detection, light guides, and electronic devices [3,4]. Organic aerogels have most frequently been obtained by sol-gel polymerization of formaldehyde (the simplest aldehyde $\mathrm{HCHO}$ with chemical structure shown in Fig. 1a) and another reactive phenolicmonomer. Among phenolic compounds (Phenol, p-Methyl phenol, o-Methyl phenol, m-Cresol, 3, 5-Dimethyl phenol, and Resorcinol), resorcinol is the most comparative reactor with formaldehyde $[5,6]$. Resorcinol (also known as 1, 3-dihydroxy benzene) has two hydroxyl groups located at the 1 - and 3-positions in the benzene ring as shown in Fig. 1b [7]. The 4- and 6- positions are located at either "ortho" (adjacent) or "para" (opposite) to the two hydroxyl groups, while the 2-position of resorcinol is located in between the two hydroxyl groups, and only ortho to the hydroxyl groups. The chemical reaction with resorcinol occurs at 2-, 4- and 6- positions. During the aqueouspolycondensation of resorcinol with formaldehyde (at molar ratio 1:2), resorcinol (as a trifunctional monomer) is capable of adding formaldehyde at 2-, 4- , and/or 6- ring positions. The reactions include: formation of hydroxymethyl $\left(-\mathrm{CH}_{2} \mathrm{OH}\right)$ derivatives of resorcinol, condensation of hydroxymethyl derivatives to form methylene $\left(-\mathrm{CH}_{2}-\right)$ and methylene ether $\left(-\mathrm{CH}_{2} \mathrm{OCH}_{2}-\right)$ bridged compounds, and disproportionate of methylene ether bridges to form methylene bridges plus formaldehyde as a byproduct [7-9]. Figure 2 illustrates the molecular polymerization of resorcinol with formaldehyde. The substituted resorcinol rings condense with each other to form nanometer-sized clusters in solution. The size of the clusters is regulated by the catalyst

*Corresponding Author: saidattia2004@yahoo.com

DOI : 10.21608/ejphysics.2017.4733

C2017 National Information and Documentaion Center (NIDOC) 
concentration (e.g., $\mathrm{NaOH}$ ) in the resorcinolformaldehyde mixture. Eventually, the clusters crosslink through their surface groups (e.g.<smiles>C=O</smiles>

(a) Formaldehyde
$\left.-\mathrm{CH}_{2} \mathrm{OH}\right)$ to form a gel. RF gels and RF aerogels are dark red in color as a result of oxidation products formed during the polymerization.

Fig. 1. Chemical structure of resorcinol and formaldehyde.

(a) Addition reaction

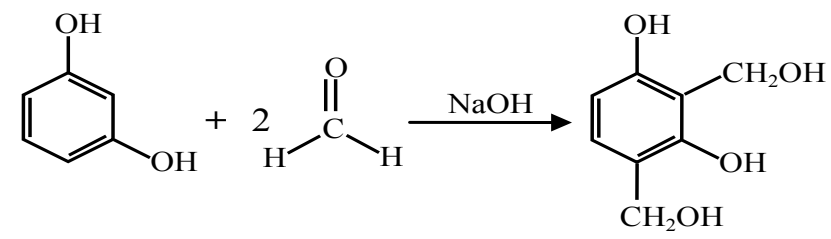

(b) Condensation reaction

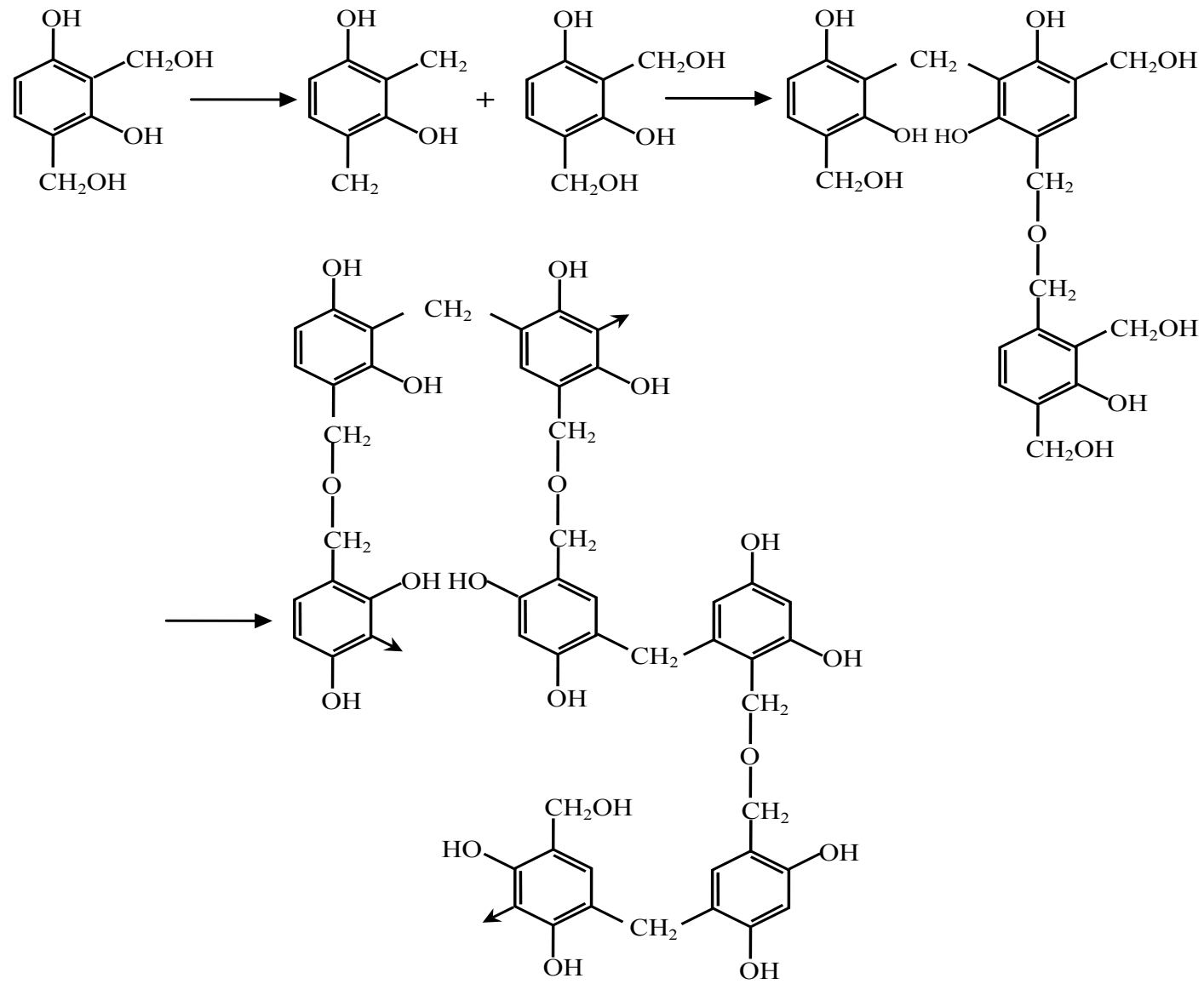

Fig. 2. Molecular presentation of the polymerization mechanism of resorcinol with formaldehyde [8, 9]. 
The resorcinol/ catalyst ratio, $\mathrm{R} / \mathrm{C}$ ratio, plays an important role in the microstructure of dry aerogels. $\mathrm{R} / \mathrm{C}$ ratio determines the size of the clusters and the morphology of the structure of the dried RF gels. During the first stage of the polymerization each cluster grows individually and their number is determined by the amount of catalyst. Subsequently they aggregate to form an interconnected structure. T. Yamamoto et al. [10] found that at low value of $\mathrm{R} / \mathrm{C}$ ratio, i.e., high catalyst concentration, the density of the nucleation centers are high and the size of the clusters is small, while, Tamon et al. [11] found that,as R/C ratio increases, the average pore size of the aerogel increases. On the other hand, Li et al. [12] found that decreasing the $\mathrm{R} / \mathrm{C}$ ratio makes the structure of dry aerogels predominantly micro-porous. Also, Mathieuetal [13] found that R/C ratio has no significant influence on the apparent surface area and the micro-pore volume.

Metal-aerogel composite can be synthesized by mixing the desired metal (in the form of its salt) with the sol-gel mixture [14]. An alternative method for preparing metal-aerogel composite involves replacement of resorcinol by its derivative containing an ion-exchange moiety [15].

$\mathrm{Cu}$ nanoparticles can be prepared by various processes such as chemical reduction, sonochemical reduction, thermal reduction, $\gamma$-radiation, ultra-visible light irradiation, laser ablation, etc. $[16,17]$. Synthesis of metal nanoparticles (except silver and gold) is often difficult due to possibility of surface oxidation of metal particles. Surface oxidation can be prevented by protecting the outer surface by using a suitable surfactant. The surfactant would also control nucleation of particles and thus act as a particle growth terminator [18].

The aim of this work is to synthesis copperaerogel composite. We present an investigation on the synthesis and characterization of pure and composite RF aerogel doped with copper nanoparticles.

\section{Experimental Methods}

\section{Materials}

Pure RF aerogels

The details of the synthesis method of pure $\mathrm{RF}$ aerogels are as follows: Resorcinol and formaldehyde were mixed together in molar ratio $1: 2$, with the addition of sodium hydroxide
$(\mathrm{NaOH})$ as a catalyst at different concentrations $(0.015,0.017,0.022$, and 0.024 wt. \%). After stirring the mixture for $30 \mathrm{~min}$ using magnetic stirrer, the mixture was poured into glass tube, which was sealed by high temperature flame. After the sealing process, the samples were stored in oven at $85^{\circ} \mathrm{C}$ for seven days. During the preparation period, the solution progressively changes color from clear to yellow to orange to deep reddish brown as a function of the reaction time. In general, the solution gel in 12-16 hr but the extended cure is necessary to complete cross linking as much as possible. After heat treatment, the hydro-gels were placed within acetone bath to exchange water with acetone. The final step was the supercritical drying of the gel. The supercritical dryer type-Quorum Technologies E3100 Series was used in order to get rid of any solvent for all the studied samples. In supercritical drying, gels are placed in a pressure vessel filled with liquefied $\mathrm{CO}_{2}$ at $15^{\circ} \mathrm{C}$ and pressure $900 \mathrm{psi}$. After a suitable time (one hour for each $1 \mathrm{~mm}$ thickness) the system was closed and the temperature was raised to $40^{\circ} \mathrm{C}$, where it was left for about $10 \mathrm{~min}$. Then the chamber was allowed to bleed slowly to atmospheric pressure. The dry RF aerogels were held in front of a high intensity light to ensure that they are transparent and that the drying process was successful.

\section{Copper colloidal nanoparticles}

Coppercolloidal nanoparticles were synthesized in the same way followed by Khannaa et al [19]. The details of the synthesis method of $\mathrm{Cu}$ colloidal nanoparticles are as follows: $5 \mathrm{~g}$ of poly (vinyl alcohol) was dissolved in $125 \mathrm{ml}$ distilled water to prepare a viscous solution. At the same time $1 \mathrm{~g}$ of copper salt $\left(\mathrm{CuCl}_{2} \cdot 2 \mathrm{H}_{2} \mathrm{O}\right)$ was dissolved in $25 \mathrm{ml}$ distilled water. After mixing the two solutions with each other and stirring for $10 \mathrm{~min}$ at room temperature, a diluted hydrazine hydrate HH (1:1) was added to the mixture with rapid stirring at room temperature for $30 \mathrm{~min}$. The color of the mixture was initially blue, then turned to green that later turned colorless which eventually afforded a brown mixture. The steps of the synthesis of nano-particles of $\mathrm{Cu}$ are illustrated in the following scheme (Fig. 3).

\section{Copper-aerogel composite}

The details of synthesis RF aerogel doped with copper nanoparticle are as follows : After preparing nano-copper colloidal as mentioned before, it has been added at different concentrations $\left(7.8 \times 10^{-5}\right.$, 
$1.56 \times 10^{-4}, 2.34 \times 10^{-4}$, and $3.11 \times 10^{-4}$ wt. $\%$ ) to the mixture during preparing RF aerogel (at catalyst concentration $0.015 \mathrm{wt}$ \%). After stirring, for more than $30 \mathrm{~min}$, the mixture was kept in ultrasonic path for more $30 \mathrm{~min}$. Finally, the mixture was poured in a test tube, which sealed by high temperature flame. The sealed tubes were kept for 7 days at a temperature $85^{\circ} \mathrm{C}$. Then, the prepared composite aerogel was cut using diamond saw in a disk shape. Finally the materials were dryingusing supercritical drying technique as described before. The schematic diagram of the preparation process is shown in Fig. 4.

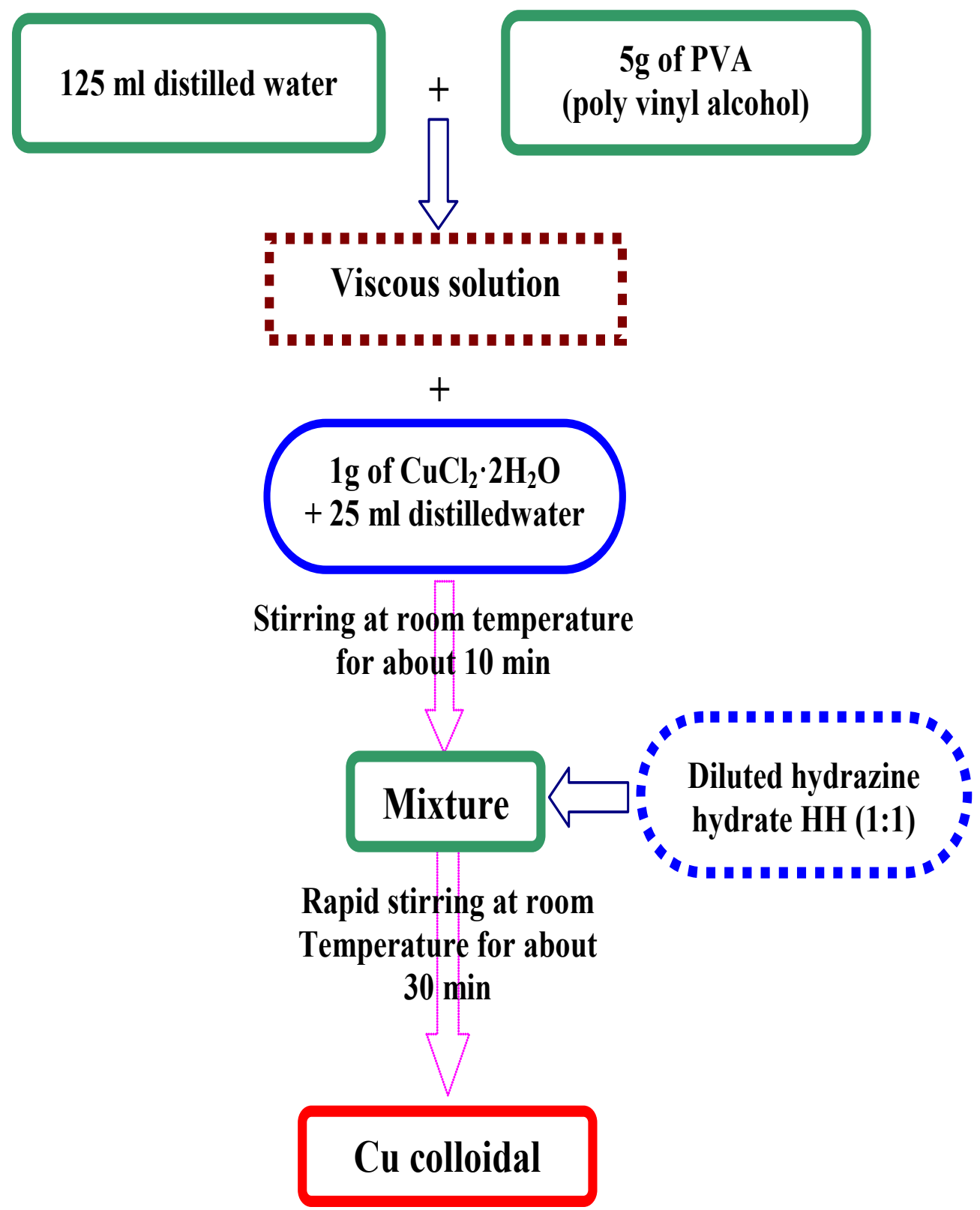

Fig. 3. Schematic diagram of synthesis $\mathrm{Cu}$ colloidal nanoparticles. 


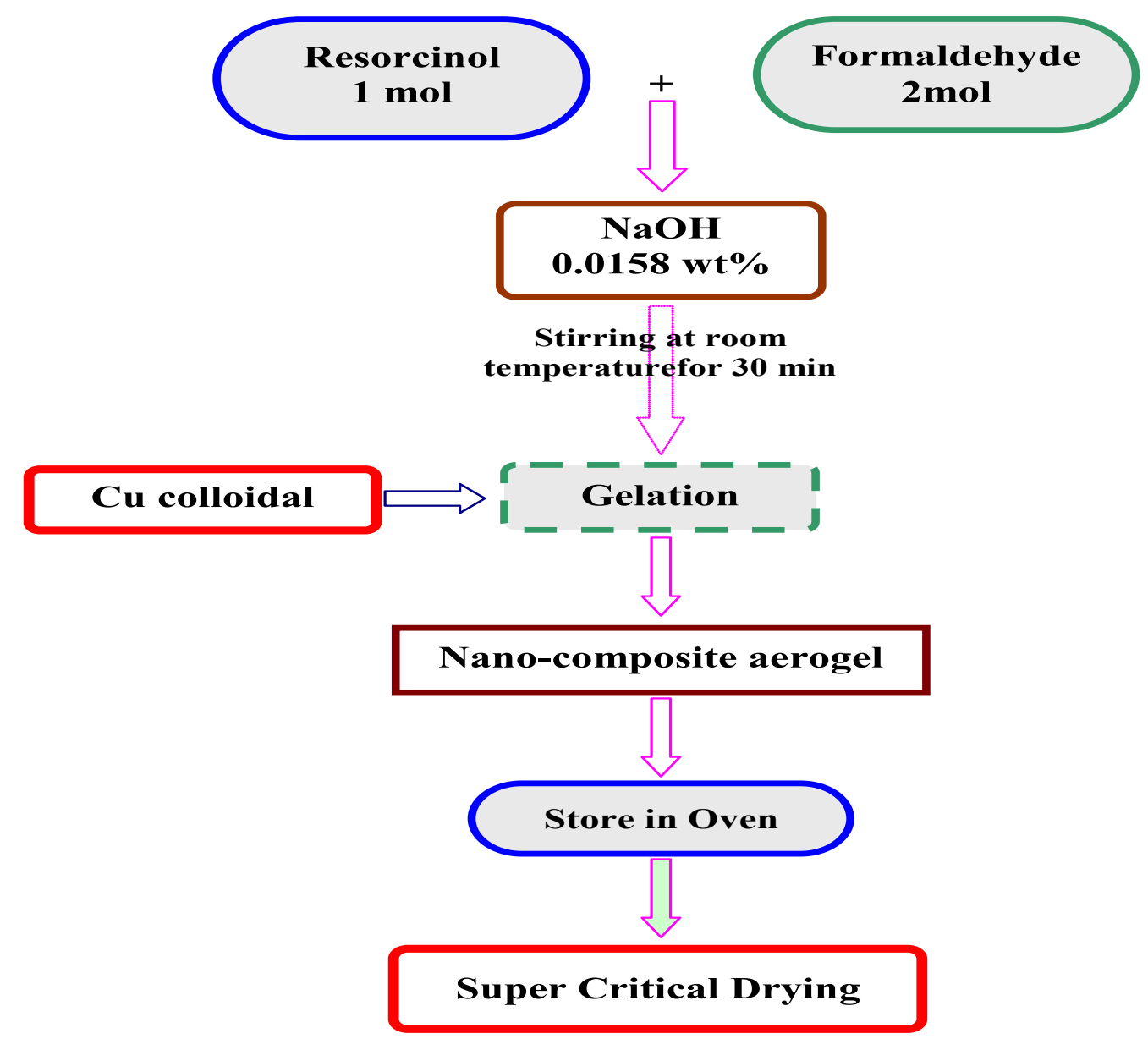

Fig. 4. Schematic diagram of synthesis $\mathrm{Cu}$-Aerogel composite.

Characterization of the materials

IR spectrometry

IR spectrometry is a type of absorption spectrometry in the infrared region of electromagnetic spectrum, at which chemical bonds vibrate in either a stretching or binding mode. The absorption frequency is determined by the molecular structure; therefore IR spectrum is used to determine functional groups in compounds. FTIR is an improved technique to make IR measurements easier and faster. FTIR spectrum is obtained from performing a mathematical Fourier Transform on the interferogram. FTIR spectra of the samples were recorded by Jasco FT/IR 4100 spectrometer (with resolution $1.928 \mathrm{~cm}^{-1}$ ) in the wave number range $400-4400 \mathrm{~cm}^{-1}$.

\section{$U V$ - VIS spectrometry}

The difference in energy between molecular bonding, non-bonding and anti-bonding orbitals ranges from 125 to $650 \mathrm{~kJ} / \mathrm{mole}$, which corresponds to electromagnetic radiation in ultraviolet (UV) region, 200-350 $\mathrm{nm}$, and visible (VIS) regions 350-800 nm. Many molecules absorb ultraviolet and/or visible light. The absorption spectrum will show a number of absorption bands corresponding to structural groups within the molecule. UV- VIS spectrum was obtained as a function of wavelength by Spectrophotometer model Shimadzu UV-2450 with resolution $0.1 \mathrm{~nm}$.

\section{Scanning electron microscopy}

Scanning electron microscope SEM operates in reflection mode to generate an image of the sample surface. SEM utilizes the low energy secondary electrons that are reflected off the sample surface upon bombardment of the sample with a high energy electron beam. SEM is a valuable tool in studying the texture, topography and surface features of powders or solid pieces. SEM requires a conductive sample surface, therefore, insulating sample surfaces are often 
coated with a thin layer of a conductive substance, such as carbon paste, or sputter coated with gold. In general SEM resolution varies from $0.5 \mu \mathrm{m}$ to $20 \mathrm{~nm}$. In this research, morphology of the samples was performed using SEM model JEOL JSM 6360 LA Analytical Scanning Electron Microscope.

\section{Particle size analyzer}

Particle size distribution for RF aerogels composite with copper was examined by particle size analyzer (PSA) type-Beckman Coulter N5 submicron particle size analyzer.

\section{Results and Discussions}

\section{FTIR spectroscopy}

FT-IR spectra were acquired between 500 and $4000 \mathrm{~cm}^{-1}$ using $\mathrm{KBr}$ pellet to ascertain the structure of pure $\mathrm{RF}$ aerogel prepared at different catalyst concentrations (C.C. $=0.015$, $0.017,0.022$ and 0.024 wt. \%) and RF aerogel composite with different concentrations of copper $\left(\mathrm{Cu} \mathrm{C} .=7.8 \times 10^{-5}, 1.56 \times 10^{-4}, 2.34 \times 10^{-4}\right.$ and $3.11 \times 10^{-4}$ wt. $\%$ at catalyst concentration, C.C. $=$
0.015 wt. \%). Figure 5 shows the IR spectrum of pure RF aerogels fine powders at different catalyst concentrations.

The spectra show six absorption bands as follows ; $v_{1}=3390 \mathrm{~cm}^{-1}, v_{2}=2934 \mathrm{~cm}^{-1}, v_{3}=1612$ $\mathrm{cm}^{-1}, v_{4}=1476 \mathrm{~cm}^{-1}, v_{5}=1222 \mathrm{~cm}^{-1}$, and $v_{6}=1092$ $\mathrm{cm}^{-1}$. The wavenumber precision of the used FTIR spectrometer is theoretically equal $\pm 0.01 \mathrm{~cm}^{-1}$. The broadband at $3390 \mathrm{~cm}^{-1}$ is characteristic of $\mathrm{OH}$ stretching vibrations in phenol. Absorption bands at 2934 and $1476 \mathrm{~cm}^{-1}$ are associated with $\mathrm{CH}_{2}$ stretching. The absorption band at $1612 \mathrm{~cm}^{-1}$ was assigned to aromatic ring stretching vibrations. The bands at 1222 and $1092 \mathrm{~cm}^{-1}$ confirm the methylene ether $\mathrm{C}-\mathrm{O}-\mathrm{C}$ linkage stretching between two resorcinol molecules (phenyl rings), which is expected in the polycondensation reaction between resorcinol and formaldehyde [20, 21]. $\mathrm{C}=\mathrm{O}$ stretching of aldehyde which show an absorption band at $1720 \mathrm{~cm}^{-1}$ was not detected, therefore, it is suggested that the sol-emulsion-gel reaction was completed [22- 24]. The change in transmission intensity can be attributed to catalyst concentration.

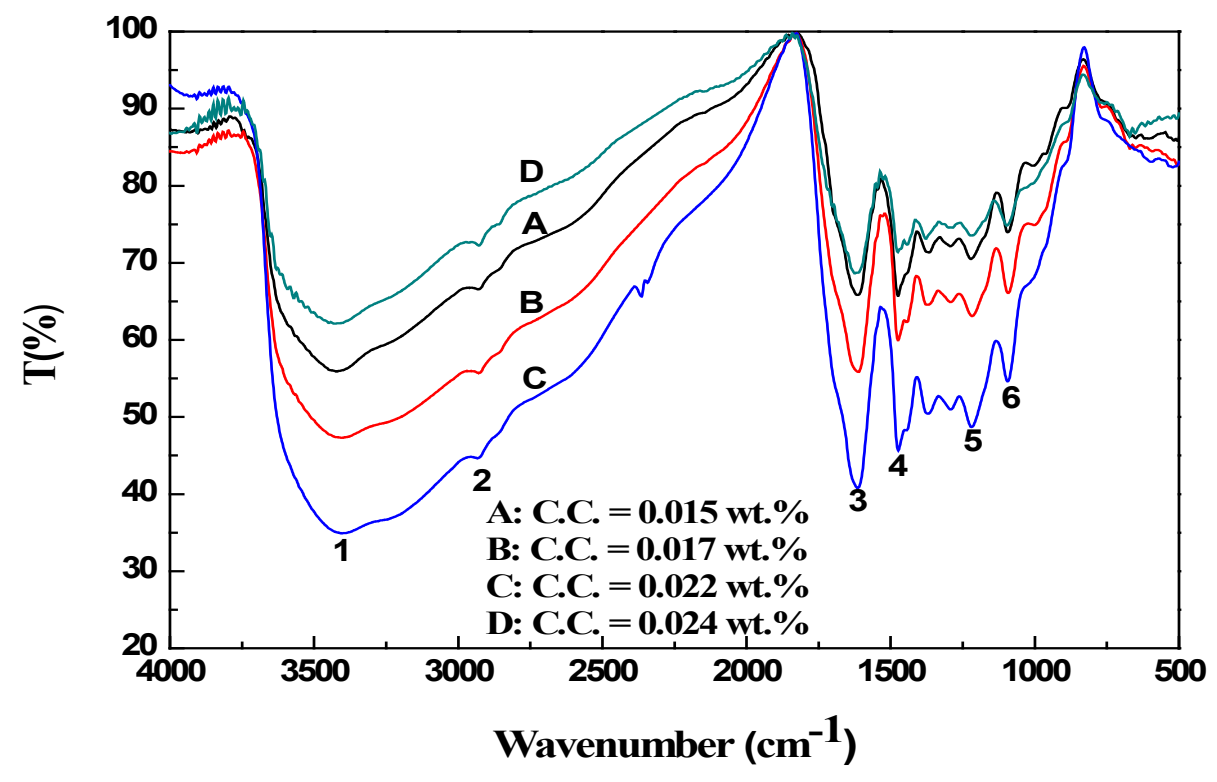

Fig. 5. IR spectra of pure RF aerogels at different catalyst concentrations.

Figure 6 shows FTIR spectra of RF aerogelscopper composite samples. Same absorption bands as that of pure RF aerogels were observed but with different transmission intensity which can be attributed to the addition of copper. Therefore, the copper don't affect the position of the absorption band of IR spectra. One may think that the copper particles do not interact with aerogel network, and they may be embedded in the pores of RF aerogel.

Egypt.J.Phy. Vol. 45 (2017) 


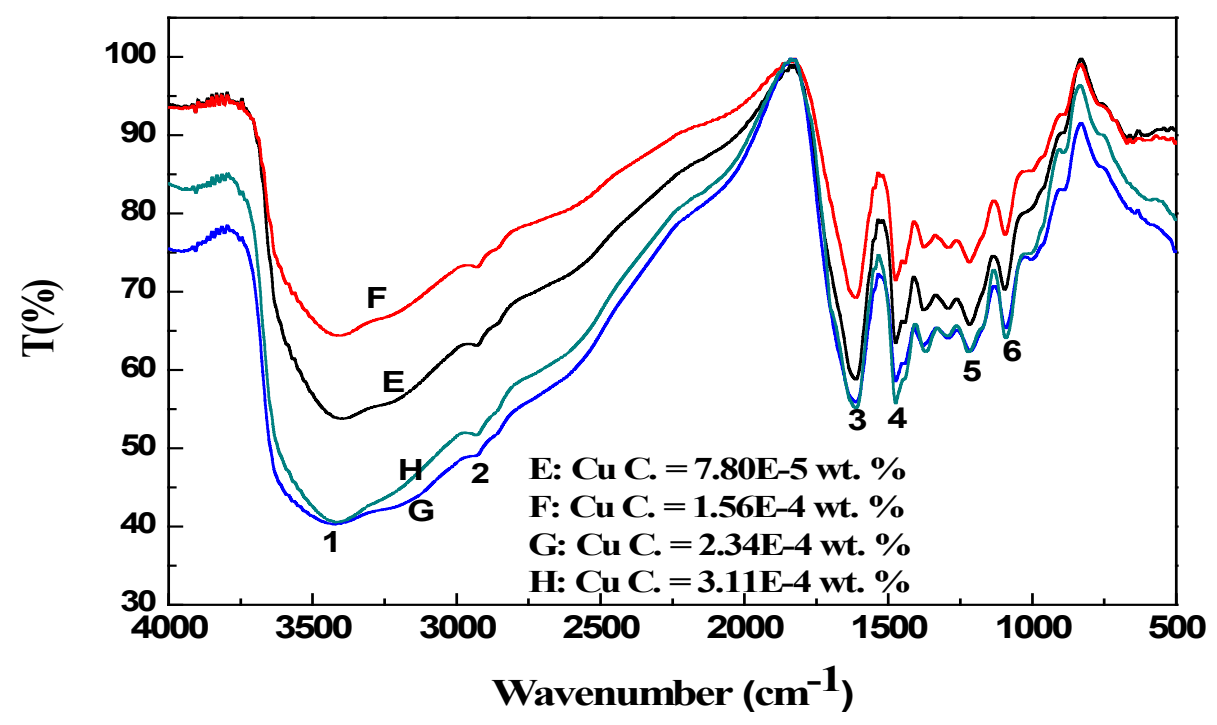

Fig. 6. IR spectra of RF aerogel composite with copper at different concentrations.

\section{$U V$-visible spectroscopy}

UV-Vis absorbance spectra have been performed (with the reference beam in water) in the wavelength rage $200-800 \mathrm{~nm}$ for pure and composite aerogels. Figures 7 and 8 show UVVis spectra of pure and composite RF aerogels, respectively. The results demonstrate the existence of a shoulder at around $500 \mathrm{~nm}$ for all samples. This shoulder causes the reddish cooler of RF aerogel $[20,21]$. The absorbance peak which appears around $300 \mathrm{~nm}$ can be attributed to alone pair of electron in oxygen atoms while the peak at $250 \mathrm{~nm}$ is due to aromatic ring [25]. It was reported that [26] Resorcinol has mainly a peak at $278 \mathrm{~nm}$ which is shifted to $250 \mathrm{~nm}$ (blue shift) in RF aerogels. This blue shift can be taken as indications of formation of RF aerogel [27]. On the other hand, Fig. 9 shows the absorption spectra for copper colloidal. A broad absorption beak is shown at $608 \mathrm{~nm}$. This result is well agreed with literature [19]. It was reported that [28] for copper nanoparticles an absorption beak occurs in the wavelength range $550-610 \mathrm{~nm}$. The broadening of the band is an indicative of wide particle size distribution of copper within the matrix [29].

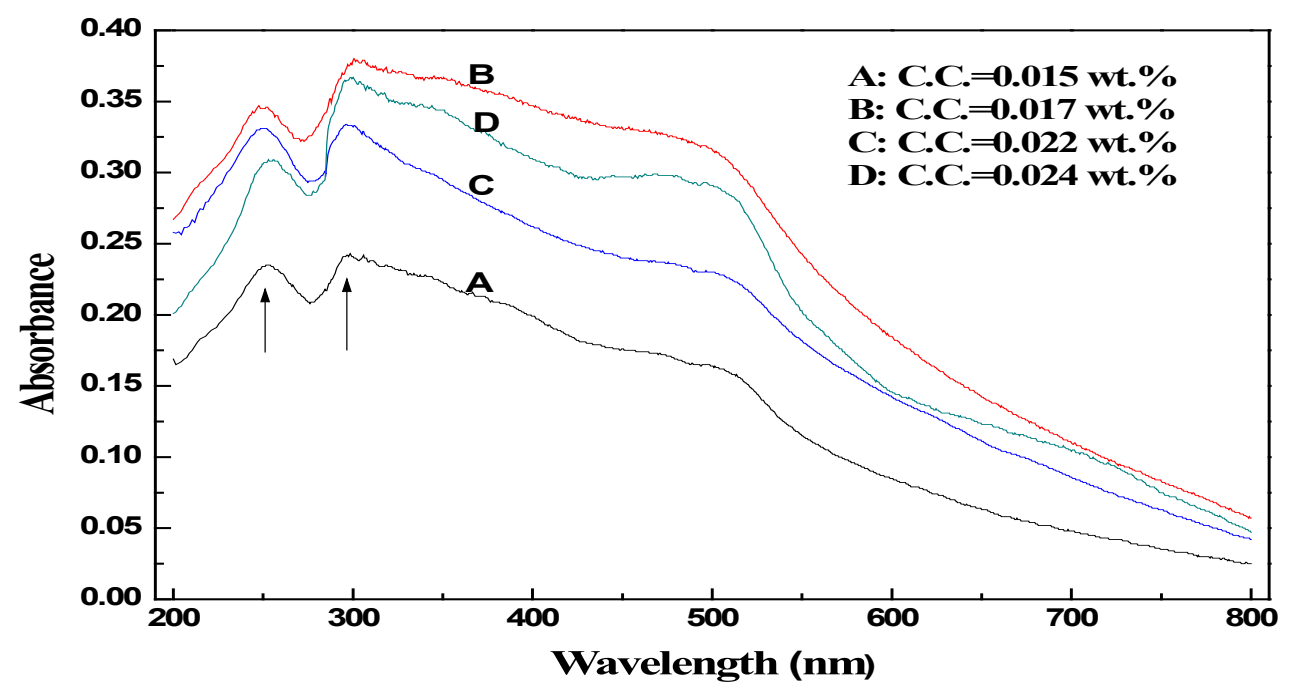

Fig.7. UV-Visible spectra of pure RF aerogels at different catalyst concentrations. 


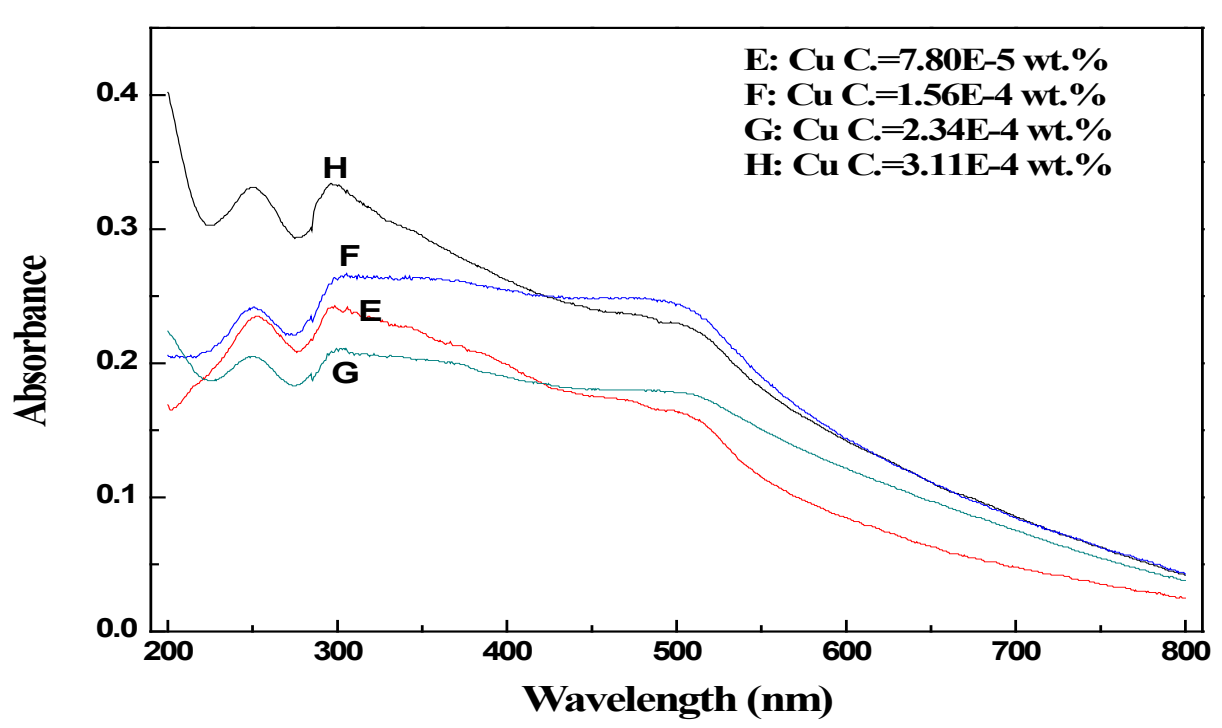

Fig. 8. UV-Visible spectra of composite RF aerogel doped with $\mathrm{Cu}$ at different concentrations.

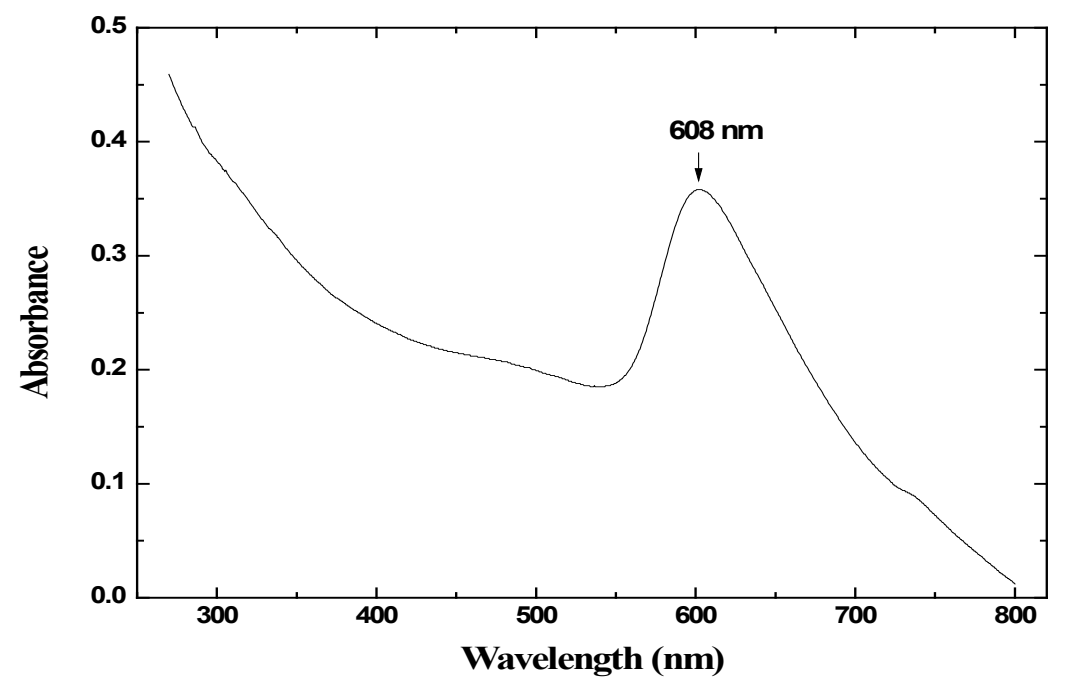

Fig. 9. UV-Visible spectrum of $\mathrm{Cu}$ colloidal.

Scanning electron microscope (SEM)

Surface morphology for both pure and $\mathrm{Cu}$ doped RF aerogels was examined by SEM image. Figure 10 shows SEM images for pure RF aerogel (the sample with catalyst concentration $0.015 \mathrm{wt}$. $\%$ ) and $\mathrm{Cu}$-doped $\mathrm{RF}$ aerogels. It is shown that the morphology of pure RF aerogel has an open cell structure with continuous porosity. The observed particles size ranges from $50 \mathrm{~nm}$ to about $100 \mathrm{~nm}$ and has large pore size. This result agrees well with literature [30-31].

For $\mathrm{Cu}$ - doped $\mathrm{RF}$ aerogels, the results show that the surface morphology has also an open cell structure with continuous porosity. The observed particle size ranges from $45 \mathrm{~nm}$ to about $200 \mathrm{~nm}$.

\section{Particle size}

Figure 11 shows the particle size distribution for RF aerogels doped with copper at different concentrations. For the sample with $\mathrm{Cu}$ concentration $\mathrm{Cu} \mathrm{C} .=7.8 \times 10^{-5}$ wt. $\%$, the particle size is distributed over a wide range $20-400 \mathrm{~nm}$, with average particle size $150 \mathrm{~nm}$. As copper concentration increases, the average particle size increases as given in Table 1 . 

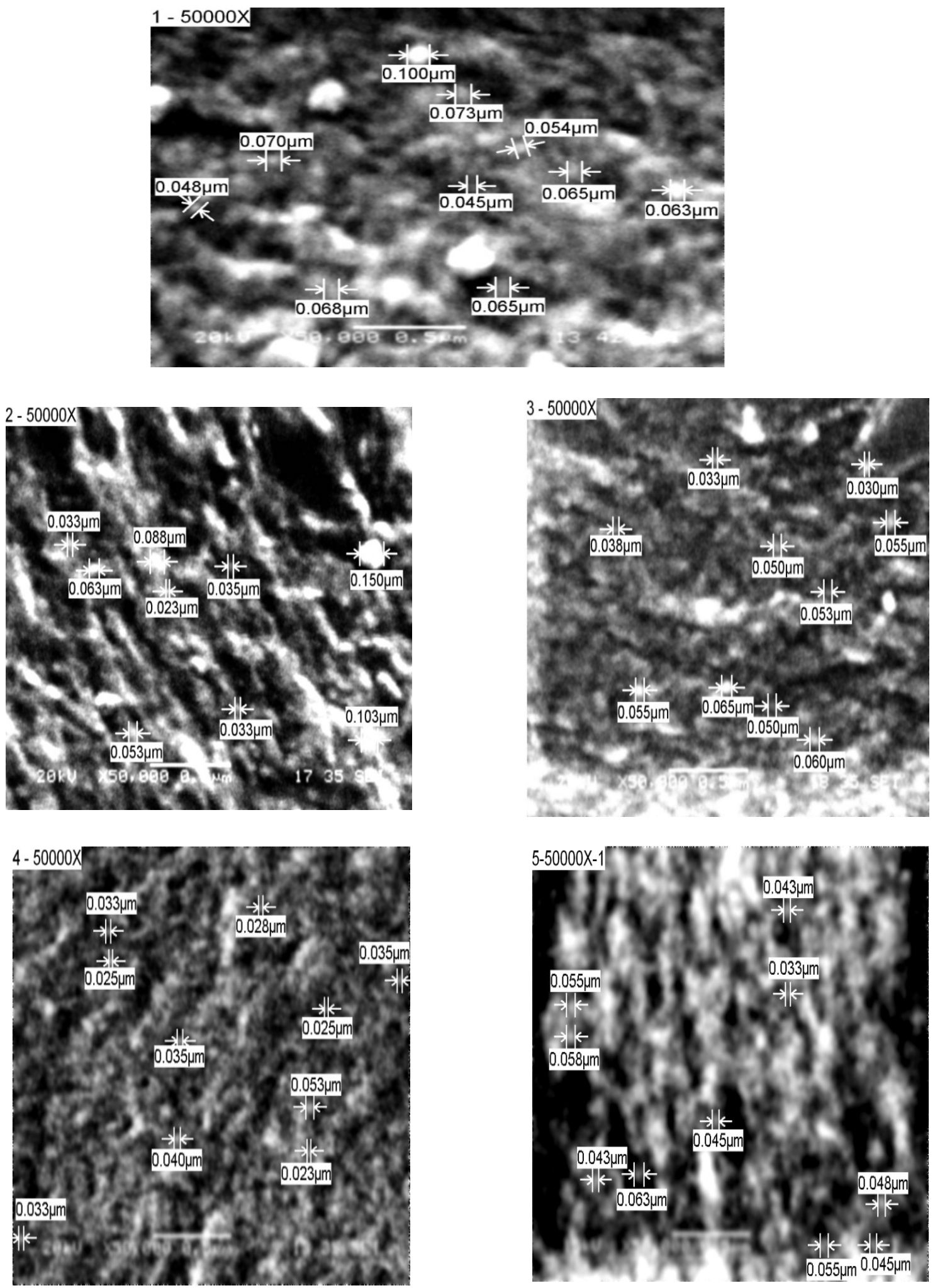

Fig. 10. SEM micrograph of pure RF aerogel at catalystconcentration $0.015 \mathrm{wt}$ \% (1), and composite RF aerogel doped with copper at different concentrations [(2): $7.810^{-5}$ wt. \%, (3): $1.5610^{-4}$ wt. \%, (4): $2.3410^{-4}$ wt. $\%$, and (5): $3.1110^{-4}$ wt. \%]. 


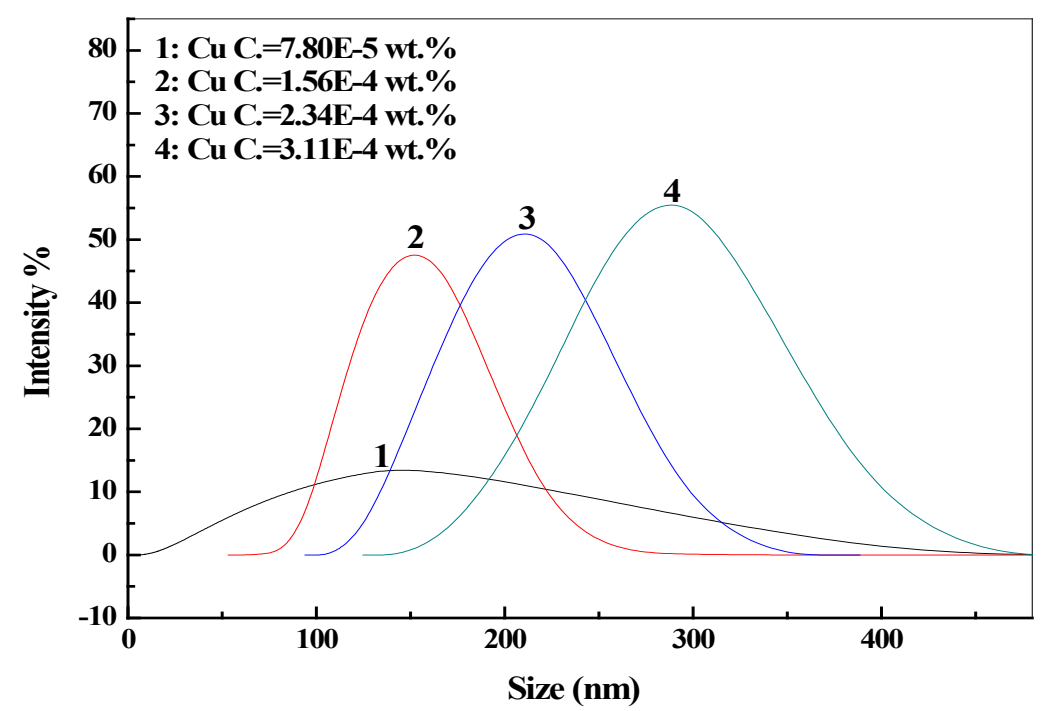

Fig. 11. Particle size distribution of $\mathrm{RF}$ aerogel doped with $\mathrm{Cu}$ at differentconcentrations.

TABLE 1. The average particle size for RF aerogel doped with $\mathrm{Cu}$ at different concentrations.

\begin{tabular}{|ccccc|}
\hline Cu Concentration wt. \% & $7.8 \times 10^{-5}$ & $1.56 \times 10^{-4}$ & $2.34 \times 10^{-4}$ & $3.11 \times 10^{-4}$ \\
Average particle size $(\mathrm{nm})$ & 150 & 170 & 210 & 290 \\
\hline
\end{tabular}

\section{Conclusion}

Nano composite RF aerogels doped with copper nanoparticles were prepared by solgel process. The results of FTIR spectra show existence of six absorption bands for pure and composite RF aerogels namely $v_{1}$ at $3390 \mathrm{~cm}^{-1}, v_{2}$ at $2934 \mathrm{~cm}^{-1}, v_{3}$ at $1612 \mathrm{~cm}^{-1}, v_{4}$ at $1476 \mathrm{~cm}^{-1}, v_{5}$ at $1222 \mathrm{~cm}^{-1}$ and $v_{6}$ at $1092 \mathrm{~cm}^{-1}$, respectively. FTIR spectra show that copper particles may not interact with aerogel network, and may only be embedded within the pores of RF aerogel. UV-visible spectra for pure and composite RF aerogels show a steep decrease of absorption with wavelength after $500 \mathrm{~nm}$ and the peak of aromatic ring $(273 \mathrm{~nm})$ is shifted to $250 \mathrm{~nm}$ in RF aerogel. The shift of the absorbance peak of aromatic ring can be taken as an indication of the formation of RF aerogel. UV-visible spectrum of copper nanoparticles shows an absorbance peak at $608 \mathrm{~nm}$ attributed to the surface plasmon excitation of copper nano spheres. SEM images of pure and composite RF aerogels show that the textural arrangement of $\mathrm{RF}$ aerogels can be described as densely packed small nodules. Particle size analyzer show that the average particle size of RF aerogels composite with copper increases with increase of $\mathrm{Cu}$ content.

\section{References}

1. Yang, J., Li, S., Yan, L., Liu, J. and Wang, F., Micropor. Mesopor. Mater. 133, 134-140 (2010).

2. Scherer, G.W., Adv. Colloid Interface Sci. 76-77, 321-339 (1998).

3. Hrubesh, L.W., J. Non-Cryst. Solids, 225, 335-342 (1998).

4. Zhou, J., Ji, Y., He, J., Zhang, C. and Zhao, G., Micropor. Mesopor. Mater. 114, 424-430 (2008).

5. Sprung, M. M., J. Am. Chem. Soc, vol. 63 (2), 334343 (1941)

6. Raff, R. A. V. and Silverman, B. H., Ind. Eng. Chem, vol. 43 (6), 1423-1427 (1951).

7. Raj B. Durairaj, "Resorcinol Chemistry, Technology and Applications; ch. 5: Resorcinol Based Resins and Applications", springer, 179-261 (2005).

8. Pekala, R. W., J. Mater. Sci. 24, 3221-3227 (1989). 
Solids, 271, 167-170 (2000).

9. Pekala, R. W., Alviso, C. T. and LeMay, J. D., J. Non-Cryst. Solids, 125, 67-75 (1990).

10. Yamamoto, T., Nishimura, T., Suzuki, T. and Tamon, H., J. Non-Cryst. Solids 288, 46-55 (2001).

11. Tamon, H., Ishizaka, H., Yamamoto, T. and Suzuki, T., Carbon, 37, 2049-2055 (1999).

12. Li, J., Wang, X., Wang, Y., Huang, Q., Dai, C., Gamboa, S. and Sebastian, P.J., J. Non-Cryst. Solids, 354, 19-24 (2008).

13. Mathieu, B., Blacher, S., Pirard, R., Pirard, J.P., Sahouli, B. and Brouers, F., J. Non-Cryst. Solids 212, 250-261 (1997).

14. Saquing, C. D., Kang, D., Aindow, M. and Erkey, C., Micropor. Mesopor. Mater. 80, 11-23 (2005).

15. Baumann, T.F., Fox, G.A., Satcher, J.H. Yoshizawa, N., Fu, R. and Dresselhaus, M.S., Langmuir, 18 ,7073-7076 (2002).

16. Šebenik, A., Osredkar, U. and Vizovišek, I., Polymer, 22, 804-806 (1981).

17. Szu-Han Wu and Dong-Hwang Chen, Journal of Colloid and Interface Science, 273, 165-169 (2004).

18. Ziegler, K. J., Doty,R. C., Johnston, K. P., and Korgel, B. A., J. Am. Chem. Soc. 123, 7797-7803 (2001).

19. Khanna, P.K., Kale, T.S., Shaikh, M., Rao, N.K. and Satyanarayana, C.V.V., Materials Chemistry and Physics, 110, 21-25 (2008).

20. Hebalkar, N., Arabale, G., Sainkar, S.R., Pradhan, S.D., Mulla, I.S., Vijayamohanan, K., Ayyub, P. and Kulkarni, S.K., J. Mater. Sci. 40, 3777 - 3782. (2005)

21. Mulik, S., Leventis, C.S. and Leventis, N., Polymer Preprints, 47 (2) 364-365 (2006).

22. Lee, J.Y., Lee, K.N., Lee, H.J. and Kim, J.H., J. Ind. Eng. Chem. 8 (6), 546-551 (2002).

23. Liang, C., Sha, G. and Guo, S., J. Non-Cryst.
24. Zhang, L., Liu, H., Wang, M., Chen, L., Carbon, 45, 1439-1445 (2007).

25. Pretsch, E., Buhlmann, P. and Badertscher, M. "Structure Determination of Organic Compounds" $4^{\text {th }}$ edition, Springer (2009).

26. Dhas, N.A., Raj, C.P. and Gedanken, A., Chem. Mater. 10 (5), 1446-1452 (1998).

27. Khanna, P.K., Gaikwad, S., Adhyapak, P.V., Singh, N. and Marimuthu, R., Materials Letters, 61 (25), 4711-4714 (2007).

28. Nandi, M., Sarkar, K. and Bhaumik, A., Indian Journal of Chemistry, 47, 815-820 (2008).

29. Gougas, A.K., Ilie, A.K., Ilie, S. and Pojidaev, V., Nucl. Instrum. Meth., A 421(1-2) 249-255 (1999).

30. Fairén-Jiménez, D., Carrasco-Marín, F. and Moreno-Castilla,C., Carbon, 44, 2301-2307 (2006).

31. Attia, S. M., Sharshar, T., Abd-Elwahed, A.R. and Tawfik, A., Materials Science and Engineering: B, 178 (14), 897-910 (2013).

(Received: 20/10/2016;

accepted: 30 /1/ 2017) 
تثخيص جيل الفورمالد هيد ـ الريسيرسينول النقي والمطعم بالنحاس

في هذا البحث تم تحضير مجمو عة من عينات جيل الفورمالد هيد- ريسرسينول الهو ائي النقي و المطعم

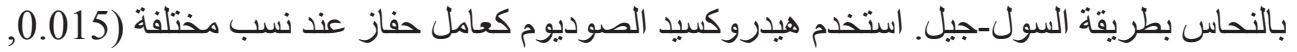

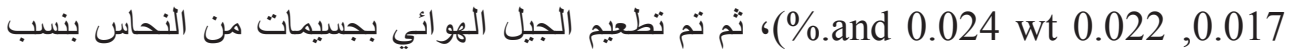

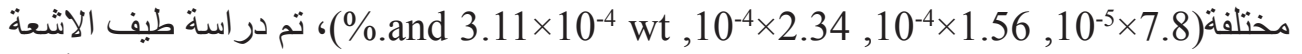

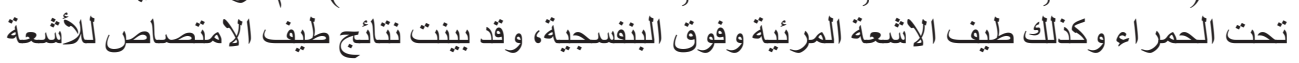

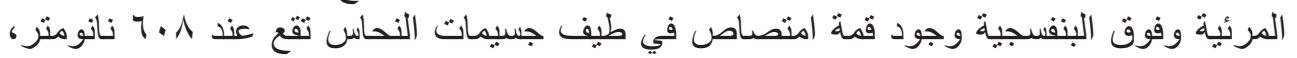
كما ان طيف الامتصاص للضوء المرئي للجيل الهو ائي النقي و المطعم ينقص بعد طوليف طول موجى 500



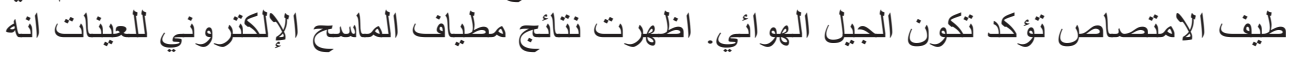

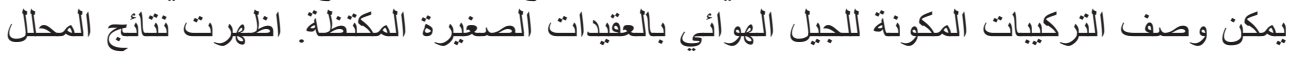
الحجمي للجسيمات ان حجم حبيبات العينات تزداد بزئ بليادة نسبة النحاس. 